This is an author produced version of a paper published in International Journal of Forest Engineering. This paper has been peer-reviewed and is proof-corrected, but does not include the journal pagination.

Citation for the published paper:

Lindroos, O. (2010) Scrutinizing the Theory of Comparative Time Studies with Operator as a Block Effect. International Journal of Forest Engineering. Volume: 21 Number: 1, pp 20-30.

http://journals.hil.unb.ca/index.php/IJFE/article/view/18222

Access to the published version may require journal subscription.

Published with permission from: Forest Products Society

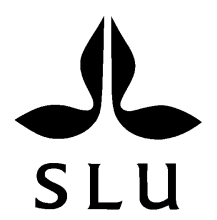

Epsilon Open Archive http://epsilon.slu.se 


\title{
Scrutinizing the Theory of Comparative Time Studies with Operator as a Block Effect
}

\author{
Ola Lindroos \\ Dept of Forest Resource Management, Swedish University of Agricultural Sciences, Sweden
}

Published 2010 in International Journal of Forest Engineering 21(1), 20-30.

\begin{abstract}
The existence of considerable productivity differences between operators is well known in forestry work studies. Several techniques have been developed to manage operator (i.e. interindividual) effects and thus enable general conclusions to be drawn. In the Nordic countries inter-individual variations have generally been managed by using 'within-operator' comparisons. The methodology is equivalent to the statistical method of blocking, when defining each operator as a block effect. Unfortunately this approach has traditionally been referred to as "comparative studies", although it only addresses one of many possible components of genuine comparative work studies. In the traditional motivation for usage of operator blocking it is assumed that productivity relationships between work methods are independent of the operator if the same operator works with both methods. Hence, comparisons of relative productivity should ignore inter-individual variations, enabling universal productivity relationships between methods/conditions of interest to be determined. Unfortunately this assumption has often been taken literally, with expectations of productivity relationships to be identical between individuals instead of on a population level. In this article the literal approach is scrutinized using the time taken by 12 operators to undertake various tasks in an experimental study of firewood processing with different machine systems and round wood types. Operators, as a population, did respond in a similar manner to treatments, but there was great variation between individuals. Hence, the assumptions of literally uniform individual productivity relationships should, therefore, be replaced by a population based theoretical foundation, which justifies the continued use of operator blocking to objectively handle the inevitable operator effect in forestry work studies.
\end{abstract}

Keywords: Work studies, relative time studies, statistical analysis, methodology, experimental studies, human performance.

\section{Introduction}

The scientific discipline of work science systematically evaluates existing and proposed humanmachine-environment systems (Björheden 1991; Wilson 1998). This is a challenge within all applications of work science (Karwowski 1991), but is especially difficult in forestry since work is carried out in a complex and highly variable environment (e.g. Vöry 1954; Samset 1990, 1992). As in other areas of work science, the differences in performance between operators are large and have been found to differ by as much as $114 \%, 300 \%, 80 \%$ and $77 \%$ between the most and the least productive operators in manual (Harstela 1975), motor-manual (Reichel 1999), mechanized (Purfürst 2009) and simulated mechanized work (Harstela 1988), respectively. To design and perform studies that evaluate the factors that influence performance, without them being confounded with other relevant factors, is therefore a great challenge in forestry.

The systematic evaluation of human-machineenvironment systems in forestry is conducted by work studies. Traditionally, the main focus has been on the system's productivity (ratio of output to input) or efficiency (ratio of input to output). For simplicity, herein the term productivity will be used when generally addressing either of the ratios. Because of the main focus, an important part of forestry work studies is time study, in which time consumption is measured in combination with the measurement of output (Bergstrand 1987; Björheden 1991). Forestry time studies can generally be divided into two categories: comparative studies and correlation studies (Bergstrand 1987; Samset 1990) (Fig. 1). In comparative studies, the objective is to compare two or more machines or methods (i.e. one or a set of relevant influencing factors) whilst other 
influences remain constant and equal. In correlation studies the objective is to describe the relationships between productivity and variations in relevant influencing factors, usually environmental factors. For practical reasons, studies normally involve a combination of comparative and correlation studies, with the specific objective normally determining how the study is classified (comparative or correlation). For instance, correlations are often used in comparative studies of the highly variable forest environment in order to enable comparisons to be made under the same conditions (e.g. the same mean tree size).

There is general consensus about the common use of the comparative and correlation approaches in forestry time studies in relation to examining influencing factors related to machines and the environment. When it comes to examining the influence that humans have on the system under evaluation, however, there are long-standing controversies especially accentuated in Europe. Unfortunately, the scientific debate is effectively obstructed by a confusing nomenclature. Figure 2 illustrates the relationship between traditional strategies for handling the human influence (hereafter called the operator effect) in forestry comparative time studies. Despite the fact that it is seldom considered, these strategies are all within the comparative study methodology but are based on slightly different approaches to scientific philosophy and practical necessities. As mentioned, forestry time studies are generally based on a comparative foundation and, moreover, with the modern advances in statistical methods the distinction to correlation studies becomes less and less visible. Thus, much of the theoretical input in this article is also applicable to correlation studies, especially since correlation elements are involved in some of the comparative study methods described.

Given that machine and environmental factors are kept constant in a comparative study, two schools are available for considering the operator effects. Either productivity data need to be corrected prior to data analyses to account for the effects or they do not. In the former, correction is normally based on correlations between operator performance and productivity, in order to normalize operators' performance to a standard level. Two distinct approaches can be found: one based on objective corrections and one on subjective corrections (Fig. 2 Boxes 1.1.1 and 1.1.2, respectively). In the search for a method for good objective correction, operators' performance has been normalized to each other by having operators work under identical conditions (e.g. the use of a standard environment and task) and through having standard operators working in parallel to all the workers in the study (Samset
1990). In the subjective method of correcting data relating to operator's performance, assessments of experts in time study are used. This is the case for the traditional method of performance rating, which has been used in both experimental evaluations and in studies focusing on production planning and setting salaries. The method focuses on the actual levels of production, but requires a large number of prior work observations in order to establish the expert assessors' norms. For further descriptions of performance rating, interested readers are referred to e.g. Barnes (1957), Wittering (1973) and Kanawaty (1992). Performance rating has a strong tradition in forestry in continental Europe and Great Britain, but has also often been criticized for its subjectivity (i.e. it is biased by the expert's interpretations already when collecting the data) (Mattson Mårn 1953; Steinlin 1955; Kärkkäinen 1975; Samset 1990, 1992). A combination of subjective and objective corrections has also been proposed (Gullberg 1995).

Those who argue against data correction prior to analyses (Fig. 2, box 1.2) assume that the operator effects are controlled for in the study design, by having all operators work with all machines and treatments. In statistical design terms this is known as blocking, in this case on the basis of the operator (Fig. 3). Naturally, an alternative approach that integrates the effect into statistical analyses would be to study many operators without blocking (or to use blocking but to ignore it in the analyses) and thus treat any effects as a component of the random error. However, the random error approach is neither appropriate nor desirable given the normally large operator effect and the small number of operators usually examined in forestry time studies. The operator blocking methodology has a strong tradition in the Nordic countries and, unfortunately, is referred to as "comparative studies" by many authors (Makkonen 1954; Harstela 1975; Kärkkäinen 1975; Harstela 1988), despite the fact that its main focus (the operator effect) just is one of many factors making up a full comparative study (Fig. 1). In addition, even within the area of controlling for the operator effect, it is just one of many methods of conducting comparative studies (Fig. 2). Since operator blocking correctly describes the method used to handle operator effects in this way, it will be used hereafter in this paper when referring to this method of controlling for operator effects (Fig. 2, box 1).

Blocking is a common statistical design in which the nuisance effect (e.g. operator) is compensated for by integrating it into the statistical analyses. However, in contrast to environmental and machinerelated factors, a given operator's performance is highly dynamic because of human physiological and psychological characteristics (e.g. Kanawaty 1992; 
Motowildo et al. 1997; Sonnestag and Frese 2002). The validity of blocking over operators is, therefore, debatable. When introduced into forestry time studies in the middle of the $20^{\text {th }}$ century, operator blocking was promoted as an objective method to decrease the variation caused by the operator and thus improve predictions of productivity for different work methods and conditions (Almqvist 1945; Mattson Mårn 1953; Makkonen 1954). Hereafter, for increased readability, work conditions will be included in the term "work methods". From the initially generally mild phrasing, the approach has developed gradually into a more rigid theoretical framework with the assumption justifying the procedure of operator blocking being that the relationship in productivity between work methods was independent of operator if the same operator works on all methods (Häberle 1965; Harstela 1975; Kärkkäinen 1975; Harstela 1988; Reichel 1997; Reichel 1999). When the universal relationships between methods have been established, it should thus be possible to predict the various productivities of operators by examining only one of the methods of interest. Hence, there are great potential savings with respect to experimental and monitoring resources with this assumption. Unfortunately the assumption has often been taken literarily, with expectations of identical productivity relationships between individuals and not on a population level. Therefore, the literal approach is scrutinized in this article and the assumptions are addressed on an individual level, in deliberate contradiction to general statistical practice. Hence, the three principles underlying the assumptions or hypothesis of operator blocking are here applied on an individual level and are defined and referred to as follows:

- P1: The relative productivity between two work methods is independent of the operator if the same operator works with both methods.

- P2: An operator's productivity with one method is predictable on the basis of productivity with the other method, by determining the universal relationship between methods.

- P3: The operator-induced variation is reduced when the same operator(s) work with both work methods, compared to having different operators for each method.

Protagonists of performance rating have criticized operator blocked studies for neglecting the well known variability in human physiological and psychological characteristics (Appelroth 1989; Thompson 1992). Sundberg (1988) has described the intense argument, which reached its peak in the middle of the $20^{\text {th }}$ century, between those advocat- ing performance rating and those supporting operator blocking studies. The remaining part of this paper addresses the principles and analysis of operator blocked studies.

Due to the relative aspects of P1 and P2, analyses have often addressed the relative productivity of different operators; productivity in terms of absolute values over operators has been considered less frequently. Due to this focus, the method has sometimes been called "relative studies" (Häberle 1965; Reichel 1997; Reichel 1999), even though analyses of both absolute and relative values can be combined. The use of absolute values enables inclusion of e.g. environmental co-variates, in order to allow comparisons between treatments under the same conditions. However, with both treatment differences and operator effects being statistically confirmed, the relative magnitude of differences between machines, for example, can lead to more robust generalizations than the absolute differences between operators (e.g Lindroos 2008).

Various authors have argued that the principles of operator blocking are valid (Almqvist 1945; Mattson Mårn 1953; Makkonen 1954; Häberle 1965), but it has not often been empirically tested. Hitherto, studies have involved either few operators $(n=4)$ and a relatively large number of repetitions of the task ( $\geq 18$ work cycles per treatment) (Harstela 1975, $1988)$ or many operators $(\mathrm{n}=101)$ but few repetitions of the task (one work cycle per treatment) (Reichel 1999). Studies involving manual workers (Harstela 1975; Kärkkäinen 1975; Reichel 1999) and machine operators (Harstela 1988) indicate that the less the work methods or conditions differ in terms of skills required by the operator, the more valid is $\mathrm{P} 1$. Some authors have analyzed the principles by comparing the coefficient of variation $(\mathrm{CV}$, i.e. standard deviation $\times$ mean value ${ }^{-1} \times 100$ ) of the productivity of different operators within the treatments and the CV when the relative productivity of operators is compared. A lower $\mathrm{CV}$ in the relative comparisons has been found by Kärkkäinen (1975), based on material by Vuoristo (1937) and Harstela (1970), and by Harstela $(1975,1988)$; these result have been interpreted as supporting P1-P3. Without focusing on CV, Reichel (1999) also provided evidence in support of P1 by comparing the pairwise relationships between four conditions (two tree types and two ground slopes), which were found not to vary between operators (the mean relative comparisons differed $\leq \pm 6$ percentage units). For P 2 it was shown that the ratio between two work conditions for a single operator is not enough to predict the ratio of a large group of operators (Reichel 1999). However, P2 has been supported in studies of small groups of operators, involving only four individuals (Harstela 
1988). One of the more recent contributions concluded that neither P1 nor P2 could be supported in a field study of manual planting (Granhus and Fjeld 2008). For the same treatment comparison, two operators' relative productivity differed between 1.4 and 8.8 percentage units, with no consistent patterns between comparisons. However, operator influences were confounded with environmental effects (different planting sites) in the study.

Due to an apparent confusion on whether or not the principles of operator blocking can, or should, be applied on an individual level, it is not surprising to find inconsistent results and an uncertainty about how to analyze and interpret the results of previous studies. Therefore, further scrutiny of the principles associated with operator blocked studies is warranted. In this article, the principles are tested by use of empirical data from 12 operators who participated in a $2 \times 2$-factorial time study of firewood production. The material is valuable because of its simplicity and the homogeneity of working conditions compared to many other forestry time studies; yet it is similar to such previous studies in its distinct operator effects.

\section{MATERIAL AND METHODS}

Two firewood production systems were studied; one including two machines and the other including just one machine. Wood of two classes was processed in tests with each machine. To serve the aim of developing the methodology and maintaining clarity, only results on the system level will be examined and only a brief description of the study methodology is given. Readers who are interested in the full description and analysis relating to machine productivities and operators' performance and perception are referred to Lindroos $(2008,2009)$.

The Cut-Split System consisted of a blade saw and a hydraulic wedge splitter, with which the two steps in the processing were conducted separately in time and space. The Processor System consisted of a firewood processor with a blade saw and a hydraulic wedge splitter, with which the two processing steps were separated in time but integrated spatially. A chunk that was cut off a log fell into the machine's splitting department and the operator actuated the splitting and waited until it had been split before the next cutting. Manual loading of the chunks to be split was thus avoided. All three machines were electrically powered and produced by Lennartsfors AB (Årjäng, Sweden).

Twelve operators were selected through snowball sampling (i.e. potential study subjects recruit other potential subjects from among their acquaintances) to compose a homogenous group of males with recurrent annual experience of processing more than $10 \mathrm{~m}^{3}$ of solid firewood with a circular saw cutter and hydraulic splitter. Grounds for excluding candidates were smoking, restraining physical conditions, experience of processing firewood volumes exceeding $50 \mathrm{~m}^{3}$ per year and experience of work with a firewood processor. Operators' mean (standard deviation (SD), interval) age, height and mass (the latter with clothes and shoes) were 69.6 years (5.5, 60-79), $1.73 \mathrm{~m}(0.06,1.65-1.85)$ and $79.9 \mathrm{~kg}(5.2$, 70.9-90.2), respectively. Prior to the study, operators were asked about their motivation for their routine firewood processing, which yielded a high mean score: 7.1 (SD 1.6) on a 10-grade scale, where 10 was the highest possible motivation for the work. Operators were instructed not to discuss the study with each other.

The study was conducted on $91.9 \mathrm{~m}^{3}$ solid birch (Betula sp.) wood, bark included. Logs $(\mathrm{n}=2,199)$ were sorted into three groups according to their root end diameter over bark. Logs in the medium root end diameter group constituted Wood Class 1, while the logs in the smallest and largest root diameter group were combined in a ratio of 5:1 to constitute Wood Class 2. The logs' diameter over bark at the top end was $>5 \mathrm{~cm}$, their lengths were between 2.0 and $6.0 \mathrm{~m}$. The mean log volume for work shifts were, respectively, $0.0538 \mathrm{~m}^{3}$ (SD $0.0015 \mathrm{~m}^{3}$ ) and $0.0338 \mathrm{~m}^{3}$ (SD $0.0028 \mathrm{~m}^{3}$ ) for Wood Class 1 and 2, with no significant differences between systems $(\mathrm{T} \leq 1.65, \mathrm{p} \geq 0.191)$. Mean log volume was tested as a covariate in the Analysis of Variance model (below) but did not contribute significantly in the model $(\mathrm{p}=$ $0.054)$ and only increased the level of explained variance $\left(R^{2}\right)$ by one percentage unit. Therefore, the mean $\log$ volume was considered equal between all treatments and operators, but with an intentional higher variation in Wood Class 2.

Each day was divided into three 90-minute shifts and an individual operator worked on all treatments over a two-day period. Between each of the three shifts during an individual working day there was a $95 \mathrm{~min}$ (SD $17 \mathrm{~min}$, interval 64-131 min) period of rest with sustenance. Operators had at least one day of rest between workdays. One operator worked with all three machines during each day. In all of the tests with the Cut-Split System the wood was processed sequentially by cutter and then splitter in a single day. Operators were randomly assigned to treatment orders and work days and the total study time was 109 hours, of which $0.9 \%$ was delay time.

Time consumption for the work was recorded through continuous time studies. Prior to each work shift, operators were told to work at their own pace and were given instructions regarding safety and standardized work routines. The chunk length was 
set to $30 \mathrm{~cm}$ and all wood chunks were to be split. Operators worked under active supervision for 5-10 minutes prior to each shift. During work shifts, operators were observed by a researcher who corrected unsafe behavior, violations to standardized work routines and helped to correct machine malfunctions. Other than those actions the researcher did not intervene during the work.

Effects of treatments were analyzed using Analysis of Variance (ANOVA) with a model containing the fixed effects of system and of wood class, the random effect of operator and the random interaction effect of system and wood class (further details are provided in Lindroos $(2008,2009))$. The random effect of operator was excluded from the model when (deliberately erroneously) examining the operator's influence on mean productivity. A general linear model (GLM) was used for analyzing the ANOVA models (Minitab 14, Minitab Ltd.). During the GLM procedure, pairwise differences were analyzed with Tukey's simultaneous test of means. This procedure allowed analyses of differences between, for example, systems and wood class combinations while also considering the operator blocking. Analyses of Pearson's correlation coefficient were used to determine variable relationships, which were visualized using simple regression lines. The significance level was set to $5 \%$.

\section{RESULTS}

The study was successful in terms of evaluating differences in time consumption between systems and wood classes. Work was conducted more efficiently with the Processor System than the Cut-Split System; wood of class 2 required more work time per $\mathrm{m}^{3}$ than wood of class 1 (ANOVA, $\mathrm{p}<0.001$ ) and there was no interaction effect between system and Wood Class $(p=0.479)$. Moreover, there was a significant difference in time consumption between operators (ANOVA, $\mathrm{p}<0.001$ ). When considering operator blocking, time consumption for all four combinations of systems and wood classes were significantly different (Tukey test, $\mathrm{p} \leq 0.007$ ). When (erroneously) excluding operator from the ANOVA model, significant differences between the main effects systems and wood classes $(p \leq 0.005)$ were still found. However, in this case, fewer differences between the four treatment combinations were identified. Significant differences between systems when working with the same wood class were found (Tukey test, $\mathrm{p} \leq 0.004$ ) but there were no significant differences within the systems when working with the two different wood classes (Tukey test, $\mathrm{p} \geq 0.100$ ). If the operator variable was excluded the level of explained variance (adjusted $\mathrm{R}^{2}$ ) in the ANOVA model decreased from $85 \%$ to $44 \%$.

The ANOVA analyses showed that even though the absolute productivity values varied between operators, operators generally responded similarly to the treatments. The result could be represented visually by arranging the data as shown in Figure 4, since the order of treatments was generally constant (Fig. 4). The order is only changed (lines intersect) on five out of 66 possible occasions. The least efficient operator required between 66\% (Cut-Split System with Wood Class 2) and 119\% (Processor System with Wood Class 1) more time than the most efficient operator (c.f. Fig. 4).

The pairwise relationship between time consumption per $\mathrm{m}^{3}$ of processed wood for combinations of systems and wood classes varied between operators; this can be seen in the highly variable vertical distances between lines in Fig. 4. The variation becomes even clearer when ratios of the pairwise combinations are plotted, as in Fig. 5, in which 18 out of 66 possible line intersections occur. If there was no relative difference between operators and random errors could be completely avoided the lines should all be horizontal, with no intersections.

The CV of the relative pairwise comparisons of time consumption per $\mathrm{m}^{3}$ of processed wood for different wood classes and systems ranged from $9 \%$ to $23 \%$ (Table 2). For two comparisons (systems within Wood Class 1 and wood classes within the Cut-Split System), the CVs for the comparisons were lower ( $\geq 8$ percentage units) than the CVs within compared treatments (Tables 1 and 2). The CV for the comparisons was equal (+1 unit) to the $\mathrm{CV}$ within one set of compared treatments (systems within Wood Class 2) and higher (4 units) than the $\mathrm{CV}$ in another set of compared treatments (wood classes within the Processor System).

For the six pairwise combinations of the four treatments, significant correlations with respect to time consumption per $\mathrm{m}^{3}$ of processed wood were found between four of them $(r \geq 0.758, p \leq 0.004)$ (Fig. 6). The combinations without significant correlations were between systems in Wood Class 2 and between wood classes in the Processor System.

\section{DISCUSSION}

\subsection{Independent productivity (P1)}

The lack of constant productivity relationships between work methods for different operators can be seen in Fig. 5. This finding is in line with Kärkkäinen's (1975) conclusion that such relationships are dependent on the operator. If the relationships were independent of operator and random errors could be 
avoided, there would have been one horizontal line for each treatment in the figure and consequently no intersections. Given the controlled experimental setting and the large variation in ratios between operators, random data collection errors are not likely to be the main reason for the irregular shape of lines. However, as a certain level of randomly generated variation inherently could be expected and might in theory be the reason for differences in the relationships, P1 is discussed below in both a more pragmatic and a more fundamental manner with both perspectives leading to the rejection of $\mathrm{P} 1$ on an individual level.

In other studies specifically designed to scrutinize $\mathrm{P} 1$, the coefficient of variation $(\mathrm{CV})$ has been used for empirical analysis. Both Kärkkäinen (1975) and Harstela $(1975,1988)$ concluded that the CV of the relative comparison between different methods was lower than the variation in absolute values within methods, and argued that this supported the principles of operator blocking studies. There are, however, several uncertainties about how CVs should be compared and what ratio should be analyzed.

First, if $\mathrm{P} 1$ is valid, the relative comparison of methods should always result in constant values for different operators. Consequently, besides the random error the $\mathrm{CV}$ in relative time comparisons should always be zero regardless of the level of $\mathrm{CV}$ within each of the two compared treatments. The $\mathrm{CV}$ of relative comparisons have, in the best cases, been as low as $3.9 \%$ (five operators, motor manual work (Harstela 1975)) and 5.7\% (four operators, mechanized simulator work (Harstela 1988)). On the other hand, Reichel (1997, p 139-141) recorded CVs of relative comparisons in the interval $21-40 \%$. In the current study the CV values for the comparisons were $9-23 \%$ (Table 2).

Secondly, if P1 is valid, absolute values in two treatments would have to co-vary to enable the stipulated constant ratio. Consequently, CV for the two treatments would be identical and would be intrinsically greater than the $\mathrm{CV}$ of the relative comparison. In the current study, the $\mathrm{CV}$ of the relationship between treatments was, indeed, always lower than the $\mathrm{CV}$ for at least one of the treatments that was used in the comparison. However, the $\mathrm{CV}$ of the ratio was lower than both treatment $\mathrm{CVs}$ in only two of the four comparisons of interest. Similar results were obtained by Reichel (1997, p 139-141), who found that most CVs for relative pairwise comparisons between treatments tallied (all within \pm 11 percentage units) with $\mathrm{CVs}$ within treatments and that the treatments' $\mathrm{CV}$ varied in magnitude; this was the case even after adjusting work time to represent standard working conditions by using regression functions. Consequently, studies with more than five operators have hitherto failed to show both the equal magnitude of the CVs in the treatments and the lower $\mathrm{CV}$ in the comparisons between treatments.

However, if the CV is an appropriate measure for evaluating the data, but still exhibits great variation, the critical question is how to discriminate between variations due to random errors and variation due to an erroneous principle. This leads to the question of whether or not there is a maximum level of $\mathrm{CV}$ for the treatment comparisons that is acceptable for supporting P1. From a practical point of view, it could be suggested that an acceptable level should be assessed in terms of the number of operators necessary in order to establish the relationship between methods at a given statistical risk. If, for instance, three operators are considered to be the maximum number acceptable if a relationship is to be established with a statistical risk of $5 \%$, the maximum level of $\mathrm{CV}$ will be $4.3 \%$ according to:

$n=4 \times\left(\frac{C V}{p}\right)^{2}$

where $\mathrm{n}=$ number of operators, $\mathrm{CV}=$ coefficient of variance $(\%)$ and $\mathrm{p}=$ statistical risk (\%) (Bergstrand 1987 , p. 24). This statistical approach, however, requires a defined number of operators in order to calculate maximum levels of acceptable CV. Such a definition can hardly be objective, which means that the method is of little value when scrutinizing principles.

Because the definition of P1 uses the term "independent of operator" there can hardly be any objective grounds to establish such an acceptable level of variation, either from a scientific or a philosophical point of view. Even if a statistical method could be found and applied to test P1 at a given statistical risk, there are logical contradictions. An individual's performance is not a static feature but the result of a combination of physiological and psychological characteristics which can vary over a short period of time, as has been demonstrated and discussed both in general (e.g. Kanawaty 1992; Motowildo, et al. 1997; Sonnestag and Frese 2002) and in forestry (Vöry 1954; Steinlin 1955; Appelroth 1980) performance and work science literature. Accordingly, in terms of an exact concordance in relative productivity comparisons between operators, P1 is not logical and has consequently never been demonstrated empirically (c.f. Fig 5). Consequently, based on its doubtful logic, in combination with empirical evidence from this and previous studies, it can be concluded that there is no support for P1 on an individual level. However, here, as well as in previous 
research, it has been shown that a population of operators responds similarly but that there is great variation between individuals.

\subsection{Productivity predictions ( $\mathrm{P} 2)$}

Even though the lack of support for P1 also implies rejection of its application P2 on an individual level, the predictive features deserve separate scrutiny. P2 has been supported by Harstela (1988), who found high correlations $(\mathrm{r} \geq 0.89, \mathrm{p} \leq 0.108)$ between two working methods for four operators working with a forwarder simulator. On the other hand, Reichel (1999), found that a model operator was not sufficient to predict the productivity of 101 studied operators and four combinations of work conditions. Within Reichel's operator group there were, however, correlations between pairwise work combinations. In the current study there were significant correlations between treatments, but only for two of the four relevant pairwise comparisons (Fig. 6). Even though all six pairwise comparisons showed a positive relationship between time consumption, the large variations in both absolute and relative comparisons (Fig. 6 and Table 2) indicate, however, great limitations for predictive features. Consequently, P2 cannot be supported on an individual level because of both the inconsistent empirical evidence and human variability with respect to physiological and psychological characteristics. However, this study, as well as previous research, shows that it is possible to predict productivity for a population of operators, but with large variation between individual operators.

\subsection{Similar productivity (P3)}

That operators respond in a similar way, but not identically, to treatments has generally been found in previous studies (Harstela 1975; Kärkkäinen 1975; Harstela 1988; Reichel 1999) as well as in the current one (Fig. 3). However, with no support for $\mathrm{P} 1$ on an individual level, the validity of the operator blocking study methodology as a way of reducing the variation caused by operators (P3) can also be questioned. Hitherto, the aforementioned findings of a lower $\mathrm{CV}$ in the comparisons between treatments than within the treatments have been taken as evidence supporting both P1 and P3. However, previous findings were contradicted to some extent in this study. Moreover, such analysis suffers inevitably from the effect of operator blocking and does not provide a valid method for evaluating P3. Consequently, with no support for P1 on an individual level, P3 needs to be tested separately. In such a test, the variation associated with the work of a set of operators, each working with e.g. two methods (operator blocked), should be compared with the variation associated with another set of operators, from which each operator only worked with a single method (not operator blocked). Consequently, the number of operators would be twice as large in the non-operator blocked set. To date, to the author's knowledge, no such test has been undertaken in forestry time studies. However, based on the finding that operators generally respond similarly to treatments, the operator blocking study methodology is likely to have the lowest operator based variation.

In the current study, different ANOVA models for analyzing the results were compared, in order to statistically examine the potential loss of analytical accuracy if operators' similar treatment responses were not considered (i.e. treating observations as operator-independent and not operator-blocked). In this case, productivity levels were statistically different between fewer treatment combinations and the level of explained variance was halved. The comparison here serves as an indicative example, but it should be pointed out that omission or removal of the operator effect, which was found to be significant, from the ANOVA model would be erroneous due the study design.

Although, as yet, no forestry time study experiments have been specifically designed to confirm P3, there are many observations that support the principle. The similar productivity levels should not, however, be taken as an excuse for not dealing with the operator-induced variation that will inevitably occur in experimental studies. To select the operator population based on desired features and in numbers selected on the basis of the expected variation in relation to the statistical accuracy required will still be important when designing successful studies.

\subsection{Strengths and limitations of the study}

A large variation in productivity was found among operators, despite their homogeneity in demographic variables and work experience. This finding conforms with the operator variation recorded in innumerable other studies. Moreover, these variations made the data material suitable in analyzing operator blocking in comparative work studies.

Compared to most other comparative forestry work studies, the operators in the current study were numerous but were also older and had not performed the work professionally. However, professionals specializing in firewood production are not common in Sweden (Lindroos et al. 2008b), so the category of experienced leisure time workers was probably the most appropriate for the studied work type. Given that results relating to the principles of operator blocking are in line with previous studies, age does not seem to be correlated to principle validity. 
The current study was performed using rather simple machine systems with little difference in the required physiological and psychological characteristics. In addition, the study was performed in an environment and with raw materials (wood classes) considerably more standardized than most forestry time studies. All these elements were considered essential in the scrutiny of operator blocking principles since it has previously been concluded that the less the conditions or work methods differ in terms of the necessary skills of the operator, the more constant are the operators' relative productivities (Harstela 1975; Kärkkäinen 1975; Harstela 1988; Reichel 1999). Despite the experimental setup, the differences in relative productivity were higher than those found in the planting study by Granhus and Fjeld (2008) even though the operator effect in their study was confounded with environmental effects (different planting sites).

Like most previous studies examining the principles of operator blocking, the work studied was not mechanized. In mechanized work, a higher proportion of mental work is required in comparison to physical work (Gellerstedt 1993). Given the many and interacting psychological features that are aggregated as mental capacities (e.g. cognitive abilities, motivation and personal traits), such a change is not likely to eliminate the operator effects. In mechanized work operators may have less opportunity to influence specific work elements due to technical limitations, but when and how work elements are combined are, nevertheless, influenced by the operator's performance (Gellerstedt 2002; Ovaskainen et al. 2004). Hence, the magnitude of operator-induced variation might decrease due to less operator influence, but it might just as well remain the same or even increase due to an eventual greater difference in mental capacities compared to physical ones. Consequently, further studies on the efficiency of the operator blocking methodology in mechanized forestry work are needed.

\subsection{Conclusion and practical applications}

In statistical analyses the focus normally lies on population means, with the general expectation of a certain level of variation over individual observations. The question is then whether or not a given treatment can be found to have an effect at the population level. In fact, this is exactly how the operator effect is handled in the methodology of operator blocking. In figure 4 the variation as well as the effect at the population level can be easily discovered. The ANOVA results also confirm statistically that the method successfully handles the operator effect. Unfortunately, the individual level justifications of operator blocking in forestry time studies
(P1-2) have too often been associated with it, instead of being replaced as statistical theory and analyses have developed. It is, therefore, time to leave the individual level assumptions behind and to continue using operator blocking for its more justifiable merits; on a population level. Since operators are more dynamic than the environment and machines, blocking might not eliminate the operator influence but would at least correct for it in an objective and statistically robust way without a priori corrections of the data. An attractive alternative is to combine theoretical simulation studies with operator blocked field studies (e.g. Lindroos et al. 2008a), in which results from a totally controlled and operatorfree setting are balanced against the multitude of variations in the field trials.

Given that the statistical methodology of operator blocking has been and most likely will continue to be considered valuable when handling the inevitable operator effects, this revision might seem to be merely cosmetic for those not familiar with the mainly European argument on how to handle operator effects. The proposed view on operator blocking is, however, important in terms of highlighting the method's strengths and limitations as it might help in solving the old and sometimes heated argument between protagonists of operator blocking studies and of performance rating (Sundberg 1988). With a population level approach to operator blocking it is easy to understand why the argument has been so long-running. In their efforts to handle the complexity of human performance, both schools have scientific limitations, namely the illogical static view of operator performance in the individual leveled operator blocking principles and the element of subjective correction in performance rating. Consequently, it is easy to criticize either approach in the belief that the other one is the lesser of two evils. Hopefully, this article will result in the continued use of the operator blocking methodology, but now with a better understanding of the logic behind it and an awareness of its justifications and weaknesses. With luck, this article might even be an eye-opener for both sides in the long-running time study argument. Hopefully we can then work together towards further methodological advances in the challenging field of forestry work science.

\section{ACKNOWLEDGEMENTS}

Thanks are due to Lars Eliasson, Janet Chaseling, Thomas Purfürst and two anonymous reviewers for their constructive and helpful comments on an earlier draft. Sees-Editing Ltd is also thanked for revising the English. The empirical data comes from a study financially supported by the Faculty of Forest 
Sciences of the Swedish University of Agricultural Sciences and the SLO Foundation's grant SLO-892.

\section{LITERATURE CITED}

Almqvist, G., 1945. Några synpunkter på tidsstudierna och deras användning inom skogsbruket [Some opinions on time studies and their use in forestry]. Norrlands skogsvårdsförbunds tidskrift, pp 23-43.

Appelroth, S.-E., 1980. Comparability of work study results. In the proceedings from the IUFRO Symposium on Stand Establishment Techniques and Technology in Moscow and Riga 3-8 Sept 1979. IUFRO Group 3.02-00. pp 414-419.

,- 1989 . The analysis and interpretation of forest work study results. In the proceedings from Proceedings of a Symposium on the Equipment/Silviculture Interface in Stand Establishment Research and Operations. Jasper, Alberta. Information Report O-X-40, Ontario Region, Forestry Canada. pp 173-183.

Barnes, R. M., 1957. Work sampling. John Wiley and Sons, Inc. New York. 283 pp.

Bergstrand, K.-G., 1987. Planning and analysis of time studies on forest technology. Bulletin 17. The Forest Operations Institute of Sweden. Kista, Sweden. 58 pp. [In Swedish with English abstract].

Björheden, R., 1991. Basic time concepts for international comparisons of time study reports. Journal of Forest Engineering, 2:2 pp 33-39.

Gellerstedt, S., 1993. Thinning with a forestry machine the mental and physical work. Research notes 244. Department of Operational Efficiency, Swedish University of Agricultural Sciences. Garpenberg, Umeå. 55 pp. [In Swedish with English summary].

-, 2002. Operations of the single-grip harvester: motorsensory and cognitive work. International Journal of Forest Engineering, 13:2 pp 35-47.

Granhus, A. and Fjeld, D., 2008. Time consumption of planting after partial harvests. Silva Fennica, 42:1 pp 49-61.

Gullberg, T., 1995. Evaluating operator-machine interactions in comparative time studies. International Journal of Forest Engineering, 7:1 pp 51-61.

Harstela, P., 1970. The effect of winter conditions on the preparation of rough-limbed spruce pulpwood of approximate length. Communicationes Instituti Forestalis Fenniae, 69:2 pp 1-54.

-, 1975. Factors affecting the consumption of working time and the strain on the worker in some forest work methods. A theoretical and empirical analysis. Communicationes Instituti Forestalis Fenniae 87.2. University of Helsinki, Faculty of Agriculture and Forestry. Helsinki. 130 pp. [In Finnish with English summary].

-, 1988. Principle of Comparative Time Studies in Mechanized Forest Work. Scandinavian Journal of Forest Research, 1988:3 pp 253-257.

Häberle, S., 1965. Die Bedeutung von Relativzeiten für eine rationelle Richtzeitermittlung. Allgemeine Forstzeitschrift, 8:pp 99-100.
Kanawaty, G. (ed.), 1992. Introduction to work study. International Labour Office. Geneva, Switzerland. 523 pp.

Karwowski, W., 1991. Complexity, fuzziness, and ergonomic incompatibility issues in the control of dynamic work environments. Ergonomics, 34:6 pp 671 $-686$.

Kärkkäinen, M., 1975. Foundations of forest work research. A critical review. Research notes No. 31. Department of Logging and utilization of forest products, University of Helsinki. Helsinki. 167 pp. [In Finnish with English summary].

Lindroos, O., 2008. The effects of increased mechanization on time consumption in small-scale firewood processing. Silva Fennica, 42:5 pp 791-805.

Lindroos, O., Bergström, D., Johansson, P. and Nordfjell, T., 2008a. Cutting corners with a new crane concept. International Journal of Forest Engineering, 19:2 pp 21-28.

Lindroos, O., Wilhelmson Aspman, E., Lidestav, G. and Neely, G., 2008b. Accidents in family forestry's firewood production. Accident Analysis and Prevention, 40:3 pp 877-886.

Lindroos, O., 2009. Relationships between observed and perceived deviations from normative work processes. Ergonomics, 52:12 pp 1487-1500.

Makkonen, O., 1954. The principle of comparative time studies in forest work. Acta Forestalia Fennica 61:14. Helsingfors. $18 \mathrm{pp}$.

Mattson Mårn, L., 1953. Arbetsstudier - Ett av arbetslärans viktigaste hjälpmedel [Work studies - One of work science's most important tools]. Skogshögskolan [Royal College of Forestry]. Stockholm. 133 pp. [In Swedish].

Motowildo, S. J., Borman, W. C. and Schmit, M. J., 1997. A Theory of Individual Differences in Task and Contextual Performance. Human Performance, 10:2 pp $71-83$.

Ovaskainen, H., Uusitalo, J. and Väätäinen, K., 2004. Characteristics and significance of a harvester operators' working technique in thinning. International Journal of Forest Engineering, 15:2 pp 67-78.

Purfürst, F. T., 2009. Der Einfluss des Menchen auf die Leistung von Harvestersystemen [The operator's influence on harvester productivity]. PhD-thesis. Institut für Forstnutzung und Forsttechnik, Technische Universität Dresden. Dresden, Germany. 307 pp.

Reichel, K., 1997. Die Variabilität der menschlichen Leistung und ihr Einfluss auf die Metodik des Zeitstudiums. Ein empirische Untersuchung der Relativzeitstudie anhand von Tätigkeiten in der Holtzernte [The variability of human performance and its impact on the methodology of time studies. An empirical study of relative time studies by means of the activity in wood harvest]. PhD Thesis. Faculty of Forestry and Forest Ecology, Georg-AugustUniversität Göttingen. 217 pp. [In German]

-, 1999. Relative time studies - An empirical survey based on individual tasks during logging operations. Allgemeine Forst Und Jagdzeitung, 170:8 pp 143-148. [In German with English summary] 
Samset, I., 1990. Some observations on time and performance studies in forestry. Communication 43.5. Norwegian Forest Research Institute. Ås, Norway. 80 pp.

-, 1992. Forest operations as a scientific discipline. Communication 44.12. Norwegian Forest Research Institute. Ås, Norway. 48 pp.

Sonnestag, S. and Frese, M., 2002. Performance concepts and performance theory. In Sonnestag, S. (eds) Psychological management of individual performance. John Wiley \& Sons, Ltd. Chichester, UK. 3-25 pp.

Steinlin, H., 1955. Zur methodik von Feldversuchen im Hauungsbetrieb [On methodology for field experiment for firewood logging]. Mitteilungen Band XXXI, heft 2. Schweizerischen Anstalt fur Forstliches Versuchswesen. Zurich. 249-320 pp. [In German].

Sundberg, U., 1988. The emergence and establishment of forest operations and techniques as a discipline in forest science. Communication 41.8. Norwegian Forest Research Institute. Ås, Norway. 107-137 pp.

Thompson, M. A., 1992. Observation and analysis of performance in forest work. In the proceedings from the IUFRO International Symposium: Work Study Measurement and Terminology. Göttingen, Germany 10-12 June 1992. Institute of Forest Engineering, Georg-August-University of Göttingen. pp 202-219.

Wilson, J. R., 1998. A framework and a context for ergonomics methodology. In Wilson, J. R. and Corlett, E. N. (eds) Evaluation of Human Work. . Taylor \& Francis Ltd. London. 1-39 pp.

Wittering, W. O., 1973. Work study in forestry. Forestry Commission Bulletin 47. London, U.K. 100 pp.

Vouristo, I., 1937. Investigations regarding the working time in the preparation of spruce pulpwood. Communicationes Instituti Forestalis Fenniae 23:1. Helsingfors. $146 \mathrm{pp}$.

Vöry, J., 1954. Analysis of the time study materials of some forest jobs. Publication No. 31. The Forest Work Studies Section of the Central Association of Finnish Woodworking Industries, Metsäteho. Helsinki, Finland. 117 pp. [In Finnish with English summary].

\section{Tables and Figures}

Table 1. Time consumption $\left(\min \mathrm{m}^{-3}\right)$ for the operators' work with system and wood class combinations. Operators are numbered in order of time consumption with the Cut-Split System and Wood Class 2

\begin{tabular}{llllll}
\hline & \multicolumn{2}{c}{ Cut-Split System } & & \multicolumn{2}{c}{ Processor System } \\
\cline { 2 - 3 } \cline { 5 - 6 } & Wood Class 1 & Wood Class 2 & & Wood Class 1 & Wood Class 2 \\
\hline Mean & 87.00 & 99.94 & & 57.49 & 74.15 \\
SD & 19.98 & 18.01 & 16.28 & 14.38 \\
CV & $23 \%$ & $18 \%$ & $28 \%$ & $19 \%$ \\
\hline
\end{tabular}

$\mathrm{SD}=$ standard deviation, $\mathrm{CV}=$ coefficient of variation $\left(\mathrm{SD} \times \mathrm{Mean}^{-1} \times 100\right)$.

Table 2. Pairwise comparisons of time consumption for all possible combinations of the two systems and the two wood classes. The two comparisons of unrelated treatments (one system and one wood class compared to the other system and the other wood class) are given in italics.

\begin{tabular}{lllr}
\hline Comparison & $\begin{array}{l}\text { Mean } \\
(\mathrm{n}=12)\end{array}$ & SD & \multicolumn{1}{c}{$\begin{array}{l}\text { CV } \\
(\%)\end{array}$} \\
\hline Processor, Wood 1 / Cut-Split, Wood 1 & 0.66 & 0.10 & 15 \\
Processor, Wood 2 / Cut-Split, Wood 2 & 0.75 & 0.13 & 17 \\
Cut-Split, Wood 1 / Cut-Split, Wood 2 & 0.87 & 0.08 & 9 \\
Processor, Wood 1 / Processor, Wood 2 & 0.78 & 0.18 & 23 \\
Processor, Wood 2 / Cut-Split, Wood 1 & 0.86 & 0.12 & 13 \\
Processor, Wood 1 / Cut-Split, Wood 2 & 0.57 & 0.07 & 13 \\
\hline
\end{tabular}

$\mathrm{SD}=$ standard deviation, $\mathrm{CV}=$ coefficient of variation $\left(\mathrm{SD} \times \mathrm{Mean}^{-1} \times 100\right)$. 


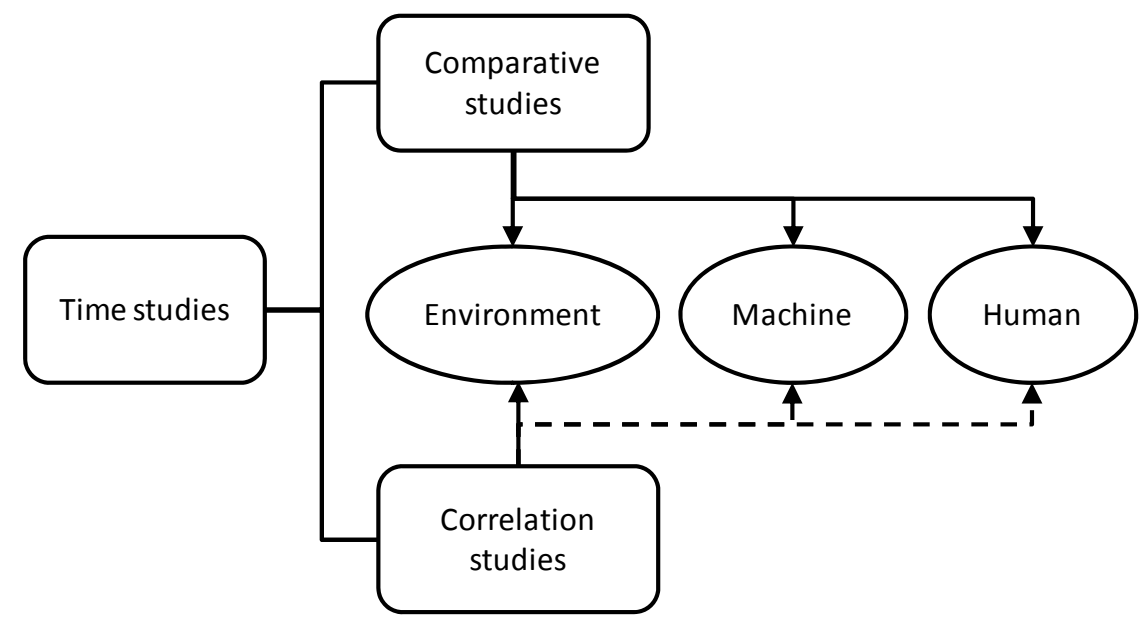

Figure 1. Model of statistical approaches used in forestry time studies to isolate the main effects from any influencing factors. Methods commonly used for specific factors are indicated by solid lines while less frequent usage is indicated by dashed lines.

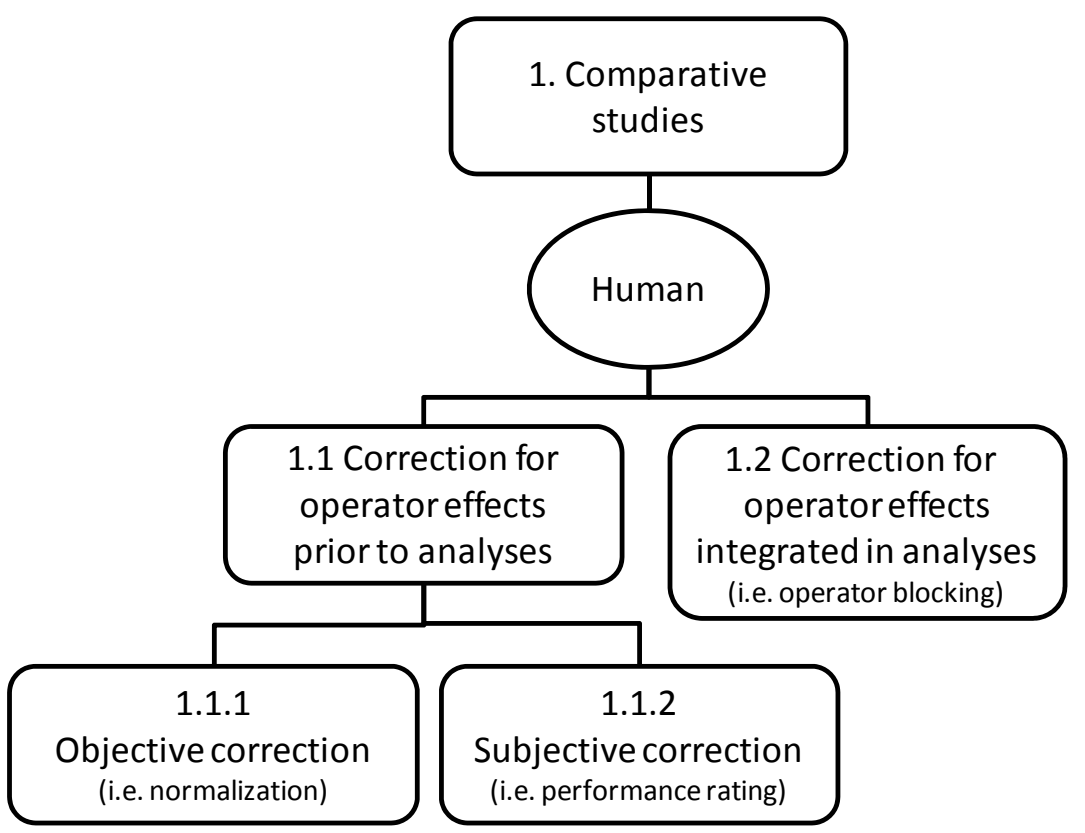

Figure 2. Model of relationships between different methods of handling the effects of operator in comparative time studies. 

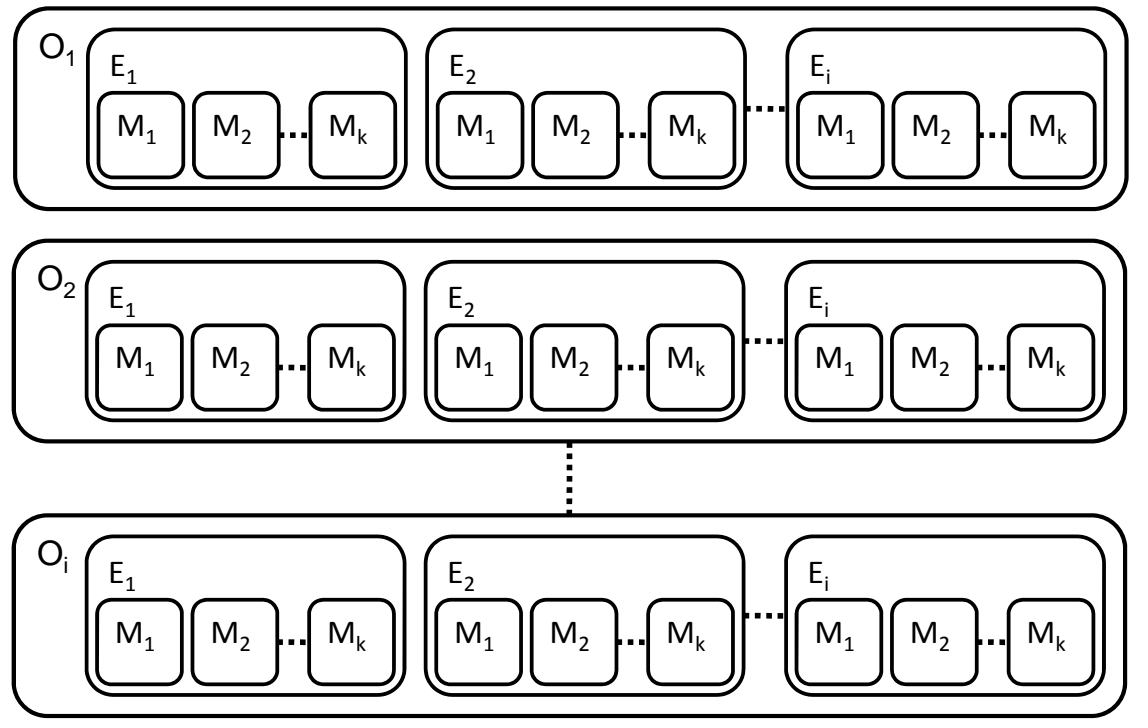

Figure 3. Model of a comparative study of different machines or methods (M) blocked for the influencing factors operator $(\mathrm{O})$ and environment $(\mathrm{E})$. The size of the experiment (i.e. the total number of observational units) is the product of the factor levels $(i \times j \times k)$.

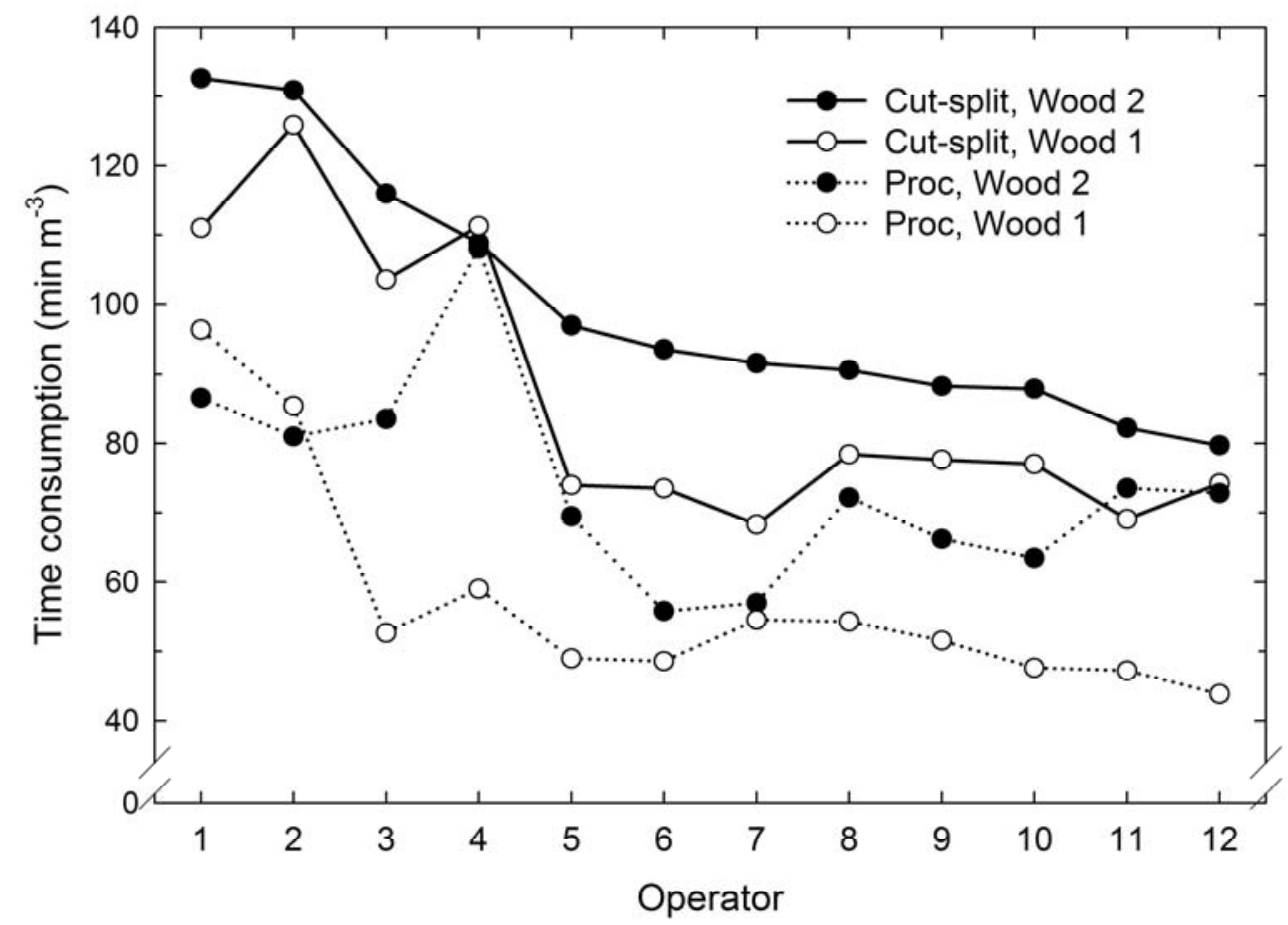

Figure 4. Time consumption of operators when working with different combinations of system and wood class, with operators given in order of time consumption with the Cut-Split System and Wood Class 2. 


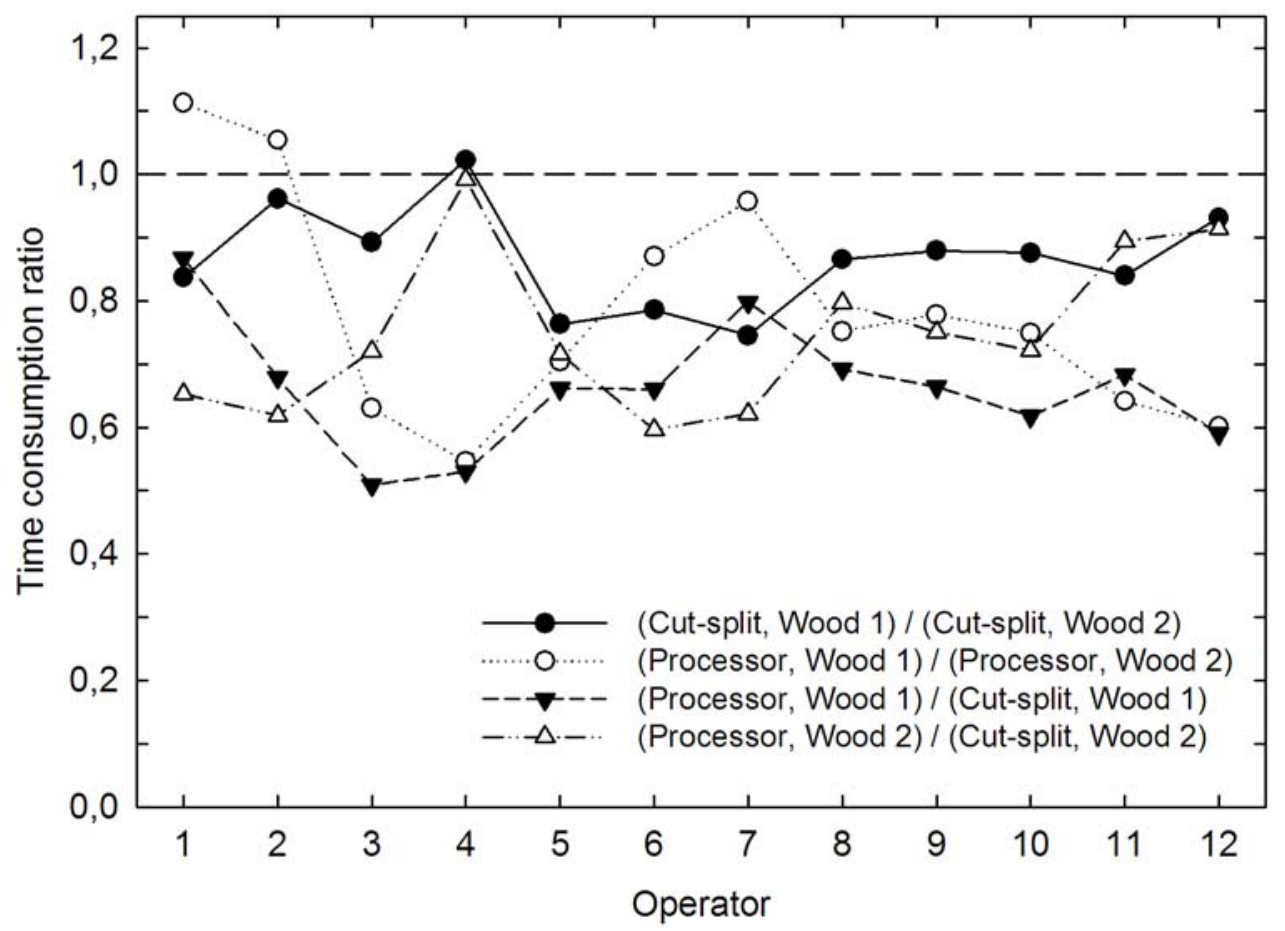

Figure 5. Ratio between time consumption for different pairwise combinations of systems and wood classes. The two comparisons of unrelated treatments (one system and one wood class compared to the other system and the other wood class) are not shown.

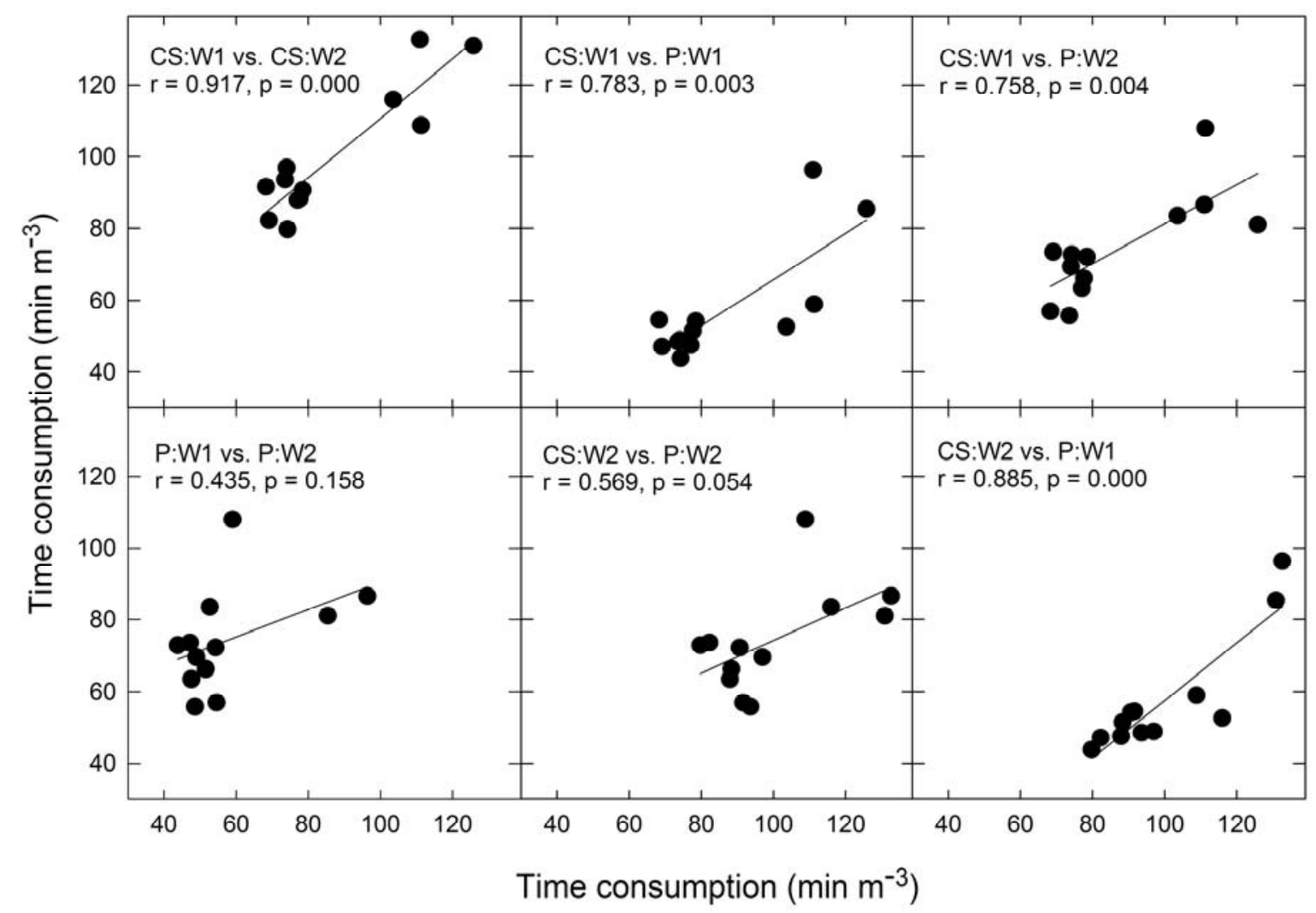

Figure 6. Correlations between time consumption with different systems and wood classes. P and CS $=$ Processor System and Cut-Split System, respectively. W1 and W2 = Wood Class 1 and 2, respectively. In each pane, the fist case of system and wood class combination is plotted on the $\mathrm{x}$-axis. 